\title{
Open Government Data of G7 Group Country: Comparison, Progress and Enlightenment
}

\author{
Chang Liü,a, Xuan Liu, ${ }^{2, b, *}$, Xiaohong Li ${ }^{3}$, Wenyan Liü, Changyan Yan ${ }^{5}$ and Jin \\ Huang ${ }^{6}$ \\ 1,2,3,4,5,6 Library of Huazhong University of Science and Technology Wuhan, Hubei, China \\ a liuchang2008@hust.edu.cn, bliuxuan@hust.edu.cn
}

Keywords: Government Data, G7, Open Data Platform

\begin{abstract}
This article selected the open data platforms of seven countries of G7 as a research object to explore the better construction strategies by recognizing current status of G7 Open Government Data platforms through investigation, thus to provide suggestions for the development of Open government data platforms in China.
\end{abstract}

\section{Introduction}

Open government data is defined as: the government shall open to the social public about the records reflecting actual facts or phenomena that are collected, processed and saved by the government through legal procedures during the performance of its duties, which should be conducted by the government on specific network platforms in a timely manner with complete content free of charge, so that users can download, use, or spread freely for legitimate purposes, but the users must not violate relevant provisions of the law. ${ }^{[1]}$

In recent years, open government data has been rapidly advanced globally. In order to learn about the plans, policies, and implementation effects of the open government Data of various countries in the world, a variety of the international organizations, including the UN and the World Bank, have conducted assessments from different dimensions. In May 2017, the World Wide Web Foundation released the Open Data Barometer Global Report (Fourth Edition), ${ }^{[2]}$ compared with open government data assessment projects of several other foreign countries, such as the World Bank's " open data readiness assessment" ${ }^{[3]}$ and the Open Knowledge International's "Global Open Data Index", ${ }^{[4]}$ and the UN's "Open Government Data Survey", ${ }^{[5]}$ the "Open Data Barometer" has the most extensive assessment dimensions and the most comprehensive content, providing the comparative data between the country and regions based on three aspects of readiness, implementation, and impact.

In the era of big data, as the largest producer, collector, user, as well as publisher of information data, the government has occupied more than $80 \%$ of the total social data. ${ }^{[6]}$ How these massive government data are fully opened, effectively developed and used innovatively, and how to promote business innovation in various fields by releasing the potential of government data to promote economic growth and social progress has become an opportunity for all countries around the world to occupy a commanding height in the era of big data.

G7 is short for G-7 Summit, which refers to the mechanism that the heads of state or government of the seven most developed industrialized countries (the United States, Japan, Germany, UK, France, Italy, and Canada). G7 was once the leader of the world economy. In 2016, the seven countries of G7 were with outstanding performances and ranked as the top 20 in the "Open Data Barometer", and the platform construction quality of its open data was ranked among the top in the world. Therefore, this study selected the open data platforms of seven countries of G7 as a research object to explore the better construction strategies by grasping current status of G7 Open Government Data platforms through investigation, thus to provide suggestions for the development of Open Government Data platforms in China. 


\section{Overall Performance of G7 Open Government Data}

\subsection{Current status of G7 Open Government Data platforms}

In order to promote the access and use of government data, the establishment of a dedicated website platform has become an important way of implementation. In recent years, all countries have established the open government data platforms. The resources include open government dataset and open data files. The total volume of resources reflects the richness of open government data, and the resource themes of open government data platform can reflect the content and coverage of the data. The resource statistics of G7 open government data platform is as shown in the following Table1.

Table 1. Overview of G7 Open Government Data Platform

\begin{tabular}{|c|c|c|c|}
\hline Country & Platform & Themes & Datasets \\
\hline U.S.A & Data.gov & $\begin{array}{l}\text { Agriculture, Climate, Consumer, Ecosystems, Education, } \\
\text { Energy, Finance, Health, Local Government, Manufacturing, } \\
\text { Maritime, Ocean, Public Safety, Science\&Research (Tol.14) }\end{array}$ & 234,623 \\
\hline U.K. & data.gov.uk & $\begin{array}{l}\text { Business and economy, Environment, Mapping, Crime and } \\
\text { justice, Government, Society, Defence, Government spending, } \\
\text { Towns and cities, Education, Health, Transport (Tol.12) }\end{array}$ & 43,098 \\
\hline Canada & $\begin{array}{l}\text { https://open. } \\
\text { canada.ca/en }\end{array}$ & $\begin{array}{l}\text { Agriculture, Arts, Music, Literature, Economics and Industry, } \\
\text { Education and Training, Form Descriptors, Government and } \\
\text { Politics, Health and Safety, History and Archaeology, } \\
\text { Information and Communication, Labour, Language and } \\
\text { Linguistics, Law, Military, Nature and Environment, Persons, } \\
\text { Processes, Science and Technology, Society and Culture, } \\
\text { Transport (Tol.19) }\end{array}$ & 78,912 \\
\hline Germany & $\begin{array}{l}\text { https://www. } \\
\text { govdata.de/ }\end{array}$ & $\begin{array}{l}\text { Population and society, Education, culture and sports, Energy, } \\
\text { Health, International topics, Justice, Legal System and } \\
\text { PublicSafety, Agriculture, fisheries, forestry and Food, } \\
\text { Government and public sector, Regions and cities, Environment, } \\
\text { Traffic, Business and finance, Science and technology (Tol.13) }\end{array}$ & 24,778 \\
\hline France & data.gouv.fr & $\begin{array}{l}\text { Agriculture and Food, Culture, Economy and Employment, } \\
\text { Education and Research, International and Europe, Housing, } \\
\text { Development, Sustainable and Energy, Health and Social, } \\
\text { Society, Territories, Transportation, Tourism (Tol.9) }\end{array}$ & $\begin{array}{l}\text { Unprovi } \\
\text { ded }\end{array}$ \\
\hline Japan & $\begin{array}{l}\text { http://www.d } \\
\text { ata.go.jp/ }\end{array}$ & $\begin{array}{l}\text { Administration and Public Finance, Business, Household, } \\
\text { Economy, Justice, Security and Environment, Transport and } \\
\text { Sightseeing, Education, Culture, Sports and Life, Land and } \\
\text { Climate, Agriculture, Forestry and Fisheries, Social Security and } \\
\text { Sanitation, Housing, Estate and Construction, Labor and Wages, } \\
\text { Agriculture, Forestry and Fisheries, Social Security and } \\
\text { Sanitation, Housing, Estate and Construction, Labor and Wages, } \\
\text { Information and Communication, Science and Technology, } \\
\text { Populaion and Households, Populaion and Households, Energy } \\
\text { and Water, Mining and Manufacturing, International (Tol.17) }\end{array}$ & 21,028 \\
\hline Italy & $\begin{array}{l}\text { https://www. } \\
\text { dati.gov.it/ }\end{array}$ & $\begin{array}{l}\text { Agriculture, fishing, forestry and food products, Economics and } \\
\text { finances, Education, culture and sport, Energy, Environment, } \\
\text { Government and public sector, Health, International themes, } \\
\text { Justice, legal system and public security, Regions and cities, } \\
\text { Population and society, Science and technology, Transportation } \\
\text { (Tol.13) }\end{array}$ & 7,028 \\
\hline
\end{tabular}

Note: Time of statistics, March 31, 2018

It can be seen from the above table that the United States, Canada, and the United Kingdom have released more topics on open government data platform than other countries, and they are rich in open government data. When accessing data from the open government data platform in France, it requires a user name and password to log in. The topics of each platform mainly include economy, education, technology, energy, environment, health, communication and transportation and arts, which covers a 
wide range of areas and includes basically all aspects of social life. Among them, there are the most detailed classifications of Japan's platform, together with the most abundant topics. The Open Government Data platforms in France have also listed topics such as tourism that have national characteristics.

As can be seen that the establishment of open government data platforms has improved the ability of the public to collect and use government information. This is worth learning from the process of the open government data in China. China has not yet established the unified national-level integrated open government data platforms. In 2015, the Plan of Action for Promoting Big Data Development ${ }^{[7]}$ issued by the State Council proposed that a unified and open national data platform should be built by the end of 2018 .

\subsection{The Scoring Performance of G7 Open Government Data Platforms in the Open Data Barometer Global Report}

"Open Data Barometer Global Report" is one of the most influential international evaluation systems in the open data field, which is aimed at revealing overall status quo and development trends of the open data of various countries around the world. Meanwhile, it provides suggestions for government work through data interpretation and analysis. Since the first release of the Open Data Barometer Global Report in $2013^{[8]}$, the World Wide Web Foundation has so far released a total of four global assessment reports, with growing number of countries assessed and increasingly wide coverage $^{[9]}$.

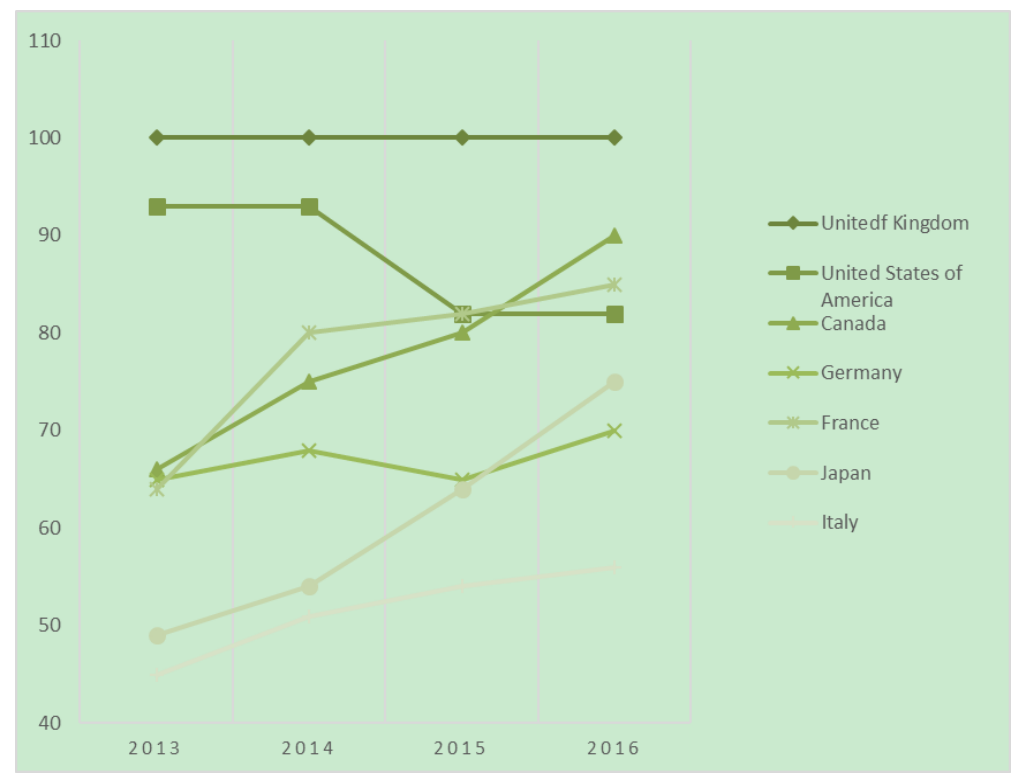

Fig. 1. The Scoring Performance of G7 Open Government Data Platforms in the Open Data Barometer Global Report(2013-2016)

It can be seen from the above figure that G7 countries have gained a very high level of open government data from 2013 to 2016, which are in top 20 around the world. Meanwhile, five countries have entered the top 10 in the world for four years. Among them, the United Kingdom got the highest score; the United States has ranked second for three consecutive years; France has risen rapidly for the first two years and has remained in the top three for three consecutive years; Canada and Japan have also been growing rapidly with quite good performances; Germany and Italy have little change in scores, but due to the overall improvement of open government data in the world, the rankings of the two countries has been declined. 


\section{The Proposals for Accelerating the Chinese Government to Move from "Open Information" to "Open Data"}

According to above analysis of the seven countries, it was found that the guarantee mechanisms of open government data in Britain, the United States, France, Canada, and Japan with good performances include four aspects: providing policies and legal guarantees, constructing the unified national open government data platforms, and establishing perfect implementation and cooperation mechanism, together with the establishment of supervision mechanism, which have provided valuable experience for the construction of open guarantee mechanism for open government data in China.

Based on research and analysis results above, China needs to pay attention to the 4 following contents in the construction process of open government data platforms: strengthen the top-level design and formulate an overall open government data policy, unifying the data platforms ${ }^{[10]}$ and develop specific open data specifications ${ }^{[11]}$, concerning about data security, and clear about the open authorization and carrying out various forms of social cooperation extensively.

Currently, government data has become the important resources for promoting the innovation and economic development. With widespread application of information technology represented by cloud computing, big data, and mobile Internet in all fields of society, it has become an important for the transformation of government to "data governance", but it also faces major challenges. On the basis of timely and accurate data release, Chinese government should improve information processing capabilities, so that the data value can be fully reflected. Meanwhile, diversified metadata can be further mined, and structured data can be visually processed to realize the value-added of the data, thus to realize the economic development by driving the innovation development through open government data.

\section{References}

[1] Jiao Haiyang, The discriminating historical justification open government data of Chinese government [J]. E-Government, vol.05, pp.19-27, 2017.

[2] [8]Open Data Barometer Global Report [EB/OL].[2018-03-03]http://opendatabarometer.org/ report.

[3] Open Data Readiness Assessment[EB/OL].[2018-03-05]http://opendatatoolkit.worldbank.org/ en/odra.html.

[4] Global Open Data Index [EB/OL].[2018-03-06]https://index.okfn.org.

[5] Open Government Data Survey[EB/OL].[2018-03-06]https://publicadministration.un.org/en/ ogd.

[6] Huang Ruhua, Li Nan.The research fo licenses for open government data. Library and Information Service, vol. 60, issue 13, pp. 5-12, 2016.

[7] Plan of Action for Promoting Big Data Development[EB/OL].[2018-03-15] http://www.gov.cn/ zhengce/content/2015-09/05/content_10137.html.

[9] Cao Yujia, Government Open Data Survival Status: Investigation Report on 19 Local Governments. Library and Information Service, vol. 60, issue 14, pp.94-101, 2016.

[10] Zheng Lei, Study on Open Government Data:Definitions, Factors and Interactions. Chinese Public Administration, Chinese Public Administration, vol. 11, pp13-18, 2015.

[11] LEE T B.5 star open data[EB /OL].[2017-11-27].http: //5stardata.info/en. 